\title{
BIM 技术在机电安装工程中的应用分析
}

\section{Application Analysis of BIM Technology in Electromechanical Installation Engineering}

\author{
兰国荣 \\ Guorong Lan \\ 南京国创机电工程有限公司 中国·江苏 南京 211100 \\ Nanjing Guochuang Electromechanical Engineering Co., LTD, Nanjing, Jiangsu ,211100, China
}

\begin{abstract}
摘要: 现如今在建筑机电安装工程中良好的采用 BIM 技术, 可以高效提升机电安装工程过程中的安全质量, 与此同时还能严 格控制工程项目施工成本。相关技术人员合理的运用 BIM 技术不光可以迅速建造出机电安装施工模型, 从中明显分析出施工 进度。而且还可以为机电安装工程中维护工作提供具有非常多的参考数据信息。论文主要对 BIM 技术在机电安装工程中的运 用进行合理的阐述。
\end{abstract}

\begin{abstract}
Nowadays, the good use of BIM technology in building mechanical and electrical installation engineering can effectively improve the safety quality in the process of mechanical and electrical installation engineering, and at the same time, it can strictly control the construction cost of engineering projects. The reasonable application of BIM technology by relevant technicians can not only quickly build the electromechanical installation and construction model, but also clearly analyze the construction progress. And also can provide a lot of reference data information for the maintenance work in the electromechanical installation engineering. This paper mainly expounds the application of BIM technology in electromechanical installation engineering reasonably.
\end{abstract}

关键词: BIM 技术;机电安装;机电工程; 应用分析

Keywords : BIM technology; Electromechanical installation; Electrical and mechanical engineering; Application analysis

DOI: $10.36012 /$ etr.v2i5.1933

\section{1 引言}

目前在机电安装工程企业中, 逐渐加强对机电工程的理 解程度和设计已经成为搭建建筑信息的一项重要环节。随着 中国信息技术的持续发展和不断创新, 客户对机电安装工程 重视程度逐渐变高, 对于 BIM 技术来说已经渐渐成为机电 安装工程企业主要技术之一。BIM 技术可以和其他的工程信 息进行融合, 从而不断完善自身机电工程, 相关人员在机电 安装过程中，合理使用 BIM 技术能够不断加强自身和现场 工作人员的合作, 使团队产生凝聚力, 从而不断地解决施工 过程中出现的各方面问题。

\section{2 机电安装过程中的特点}

\section{1 对于施工人员的技术要求较高}

施工人员在机电工程施工过程中，为提升自身操作技 术，因此需要施工单位及时引进新型施工材料和机械设备。
机电工程安装工作相比较于建筑构筑物而言, 在施工质量检 测方面具有一定差异性。其中最大的差异就是质量评估和工 程验收。但是由于机电安装工程实干时,所需要的材料类型 较多, 而且对施工人员自身的专业施工技术要求较高, 因此 施工单位需要投人大量人力或物力等等, 并且相关施工人员 自身还需要具备灵活的施工经验。

\section{2 机电安装工程覆盖面较为广泛}

对于机电安装工程来说, 其中涉及到的多方面较为广 泛, 在消防工程中就涉及到机电安装工程。与此同时施工人 员在机电安装过程中, 采购人员还需要注重设备的采购环 境、设备的安装环境以及设备的调试。由于机电安装工程其 中涉及到的工程较多, 因此施工人员应当充分运用自身良好 的施工技术进行高效施工。

\section{3 合理分析 BIM 技术的特点}

对于 BIM 技术来讲, BIM 技术是一项具有非常模拟化

【作者简介】兰国荣(1978 ), 男, 汉, 江苏南京人,工程师, 从事建筑电气研究。 
的模型，主要会应用到前期、中期、后期这三部分环节中。 BIM 技术是建筑行业中最先进的信息技术, BIM 技术可以 将建筑施工过程中从设计到管理进行数据化。同时建造出三 维模型, 将建筑物中的各种不同时间的参考数据加入模型 中。这样可以让相关建筑人员从中获得更为精确的数据, 持 续提升自身决策的合理性。与此同时 BIM 技术还可以对施 工过程中每个阶段进行有效沟通,避免出现施工过程中的孤 立情况, 可以有效避免数据信息的流失。因此相关人员在建 设机电工程前期, 应当充分建立 BIM 模型。BIM 模型能对工 程中的设计进行三维化的处理, 使模型能够进行自行检验, 模型在自我检验的过程中便能够完成建筑施工各个管道的 碰撞问题, 及时生成相关报告。使施工人员可以从相关报告 中清楚看到各个管道的分布。现阶段很多公司使用 BIM 技 术后可以对建筑施工中机电管线进行检查工作, 检查后充分 运用机电系统高效进行计算。设计师通过灵活运用 BIM 技 术可以设计出完善的设计成果, 设计人员完成机电安装工程 设计工作后。可以预测出管道的具体用量, 从而减少建筑施 工中的成本。BIM 技术中的软件可以为相关设计师提供信息 良好沟通的条件, 相关设计人员可以运用 BIM 技术中的软 件完成动画模拟和建筑施工的过程。可以有效的通过动画形 式展示出相应的建筑施工场景, 相关设计人员在清楚看到相 应的建筑施工场景之后, 可以及时采取相应的应对措施。

\section{BIM 技术在机电安装工程中的运用}

\section{1 设计师应当统计相应的施工材料}

相关设计师在设计相应建筑中信息模型时,便会对每一 个建筑信息都设置出相应的参数。因此设计人员在建造虚拟 模型时, 应当对每一个机电工程中的系统进行有效的评估, 然后根据系统的实际情况选取适合的材料数量, 从而进一步 的提升机电安装工程整体设计效率。此种方式能够有效的提 升预算的精准度，设计人员在设计前期, BIM 技术软件已经 设置较多的䇻选条件, 因此可以为相关人员对䇻选条件提供 一定程度的方便性。对于采购环节中的相关人员来讲, 可以 根据机电工程中的进度建立相应的 BIM 模型，从中获得一 些数据信息, 在从 BIM 模型中还可以获得建筑材料的使用 状况, 这种情况会使相关管理人员在今后的物资管理工作中 具有便捷性。设计人员充分运用 BIM 技术前期,一般都会采 取设备工程根据管理者的经验来安排具体工作人员, 对于相
应的材料分配一般都是根据施工工人的实践操作经验进行 分配。

\section{2 施工单位应当积极提升机电安装工程中的成本 控制能力}

施工人员在运用 BIM 技术之前, 应和生产人员在施工 前期对于可能会出现的技术难点准备好相应对的方法, 从而 合理安排相应的施工计划, 减少由于线路安排不合理导致返 工现象的出现, 与此同时施工单位应当不断压缩人工成本, 从而减少工程质量下降。对生产统计工作人员, 可以提前设 置出数据材料, 将三维模型导入到软件之后, 软件就可以自 动计算出相关的实际费用。并合并到处保量的内容中, 不断 的汇总产生多期报量。很多公司通过 BIM 技术可以将专业 技术性问题在施工前期进行及时解决, 从而不断提升自身施 工的预判性, 降低施工中产生的难点。

\subsection{BIM 技术在管线综合设计中的应用}

机电工程项目通常需要连接数量庞大的管线, 尤其在进 行高层建筑内部的机电工程施工时, 管线的设计尤其重要。 利用 BIM 技术, 设计人员可以对管线的连接、部署进行更加 科学的设计, 让机电工程的整体效率得到提升。首先, 设计人 员应利用 BIM 技术围绕管线设计建立三维模型, 并通过相 应的软件检测机电工程内部管线之间的碰撞情况,一旦发现 管线之间发生摩擦或互相阻碍, 要对相应的位置进行优化设 计。不仅能够提高管线的使用效率, 还在一定程度上降低管 线在使用的过程中因为互相碰撞或摩擦降低性能, 甚至产生 破损等风险。

\section{4 利用 BIM 技术对现场施工方案进行优化}

BIM 技术在使用过程中, 不光能胜任前期设计的工作, 还能针对施工现场的一系列问题进行优化设计。在施工遇到 问题时, 设计人员可以对施工现场的各种信息进行分析, 并 利用 BIM 技术进行逐层分析, 针对问题给出解决方案。而 且, 由于机电工程施工现场情况比较复杂, 一旦参数交底工 作出现失误, 就需要技术人员对整个工程进行重新梳理, 不 仅降低工程的推进速度, 还为企业增加无谓的损耗, 增加成 本。为解决这一问题, 设计人员可以将 BIM 模型导人计算机 中, 对施工现场进行动态模拟, 让施工人员能更加清晰地发 现问题所在, 予以解决。BIM 技术对于施工现场的模拟是其

(下转第 67 页) 
械生产企业要想在激烈的市场竞争中突显出来, 必须减少生 参考文献

产成本的投入,提高生产产品的整体质量,引进更多先进的

[1] 程焕生.基于智能化的机械设备电气自动化技术应用研究 $[\mathrm{J}]$.内 燃机与配件,2019(17):103-104.

科学技术,将自动化技术应用到机械制造生产过程中,生产

出更多高质量的产品，进一步提升企业生产技术的整体水

[2] 罗强,杨翼,张德昌, 王雅秋. 机械制造电气自动化控制可靠性 问题研究[J].农家参谋,2019(20):192.

平, 提升企业的综合竞争实力, 为机械制造企业的持续、稳定

[3] 司东杰.电气工程自动化的智能化技术应用[J].工程建设与 设计,2018,No.384(10):267-268.

\section{发展提供保障。}

\section{(上接第 64 页)}

得到广泛应用的重要原因之一, 技术人员要多加利用,让机 电工程施工现场的问题得到快速解决。

\section{5 结语}

对于机电安装项目负责人来说,应当充分根据客户的基 本需求对相关项目进行精准设计。设计人员在设计时应当充
分提升 BIM 模型中的深度，有效的根据图纸尺寸做好相应 的建模活动。

参考文献

[1] 李青,李松,陈良.BIM 技术在机电安装工程中的应用[J].现代工业 经济和信息化,2019,9(08):76-77

[2] 刘宗明,王晞媛,史素佳.B IM 技术在大型公共建筑机电安装工程中 的应用研究「J.科技经济导刊,2019,27(29):50-51. 